\title{
Customer Life Cycle Management- Time and Beyond...- Expertise recognized by clients, Analysts like.
}

\author{
Medha Gore J \\ India
}

\begin{abstract}
The marketing mix management paradigm has dominated marketing thought, since it was introduced 40 years ago. New approaches are making their presence, thus setting an era trumpeting loudly the emergence of new stream of Marketing - Relationship Marketing calling for understanding consumers individually and their association with the Organization over a long term, thereby creating a phenomenon called Customer Life Cycle Management.

In view, businesses have adopted applying Customer life Cycle Management to customers and users experience. This embodies the notion of "suspects" who potentially may benefit from acquiring a physical product, non-physical product and/or service offering but may not be aware of it, :'prospects' who may be ready, willing and able to acquire an offering and need to decide on a purchase: actual customers who were prospects who 'signed up': repeat customers who made more purchases and use more than one product or 'value proposition'

Leadership comes from providing these customers, users and network 'players' with excellent appropriate experiences throughout customer life cycle.

Index Words: Customer, Consumer behavior, Intangible associations, Marketing thought, Prioritizing systems
\end{abstract}

\section{Introduction:}

Perhaps the fundamental issue facing marketing today is that relating to identify and progress of discipline. While recognizing the existence of a range of perspectives on this issue, one can also note two distinct clusters of belief. On the one hand there are those who emphasize the unity and coherence of the discipline and who place their belief in an orderly progression whereby one paradigm succeeds another. Alternatively there is a growing voice within the academy which celebrates pluralism, multiplicity and difference. In the midst of this only one voice echoes loudly and i.e of the customer, for the customer and to the customer. The organizations that don't follow the race will eventually be heading towards extinction or will prove rabbit in the race of tortoise...

Fast forward 20 years to 2015, with 20/20 vision. Trying to cruise into the time to explore what's the key to unprecedented marketing success in an on-demand world? In this google era, your prospectus and customers get information, make decisions, and communicate in an entirely new way. Which means you need new ways to catch their eyes and their business?

The marketing mix management paradigm has dominated marketing thought, since it was introduced almost 40 years ago. Today, this paradigm is beginning to loose its position. New approaches are making their presence, thus setting an era trumpeting loudly the emergence of new stream of marketing.-Relationship marketing, calling for understanding consumers individually and their association with the organization over a long term, thereby creating a responsibility on the organizations to understand customer association, giving rise to a phenomenon called Customer Lifecycle Management.

In my view, businesses have adopted applying customer lifecycle management to customers and users experience. This embodies the notions of 'suspects' who potentially may benefit from acquiring a physical product, non-physical product and/ or service offering but may not be aware of it: 'prospectus' who may be ready, willing and able to acquire an offering and need to decide on a purchase: actual customers who were prospectus who 'signed up' :repeat customers who made more purchases and use more than one product or 'value proposition,. These customers form a part of a value network which refers to supply chain, demand chain(channels/ routes to market) and various customers as well as contingents(e.g regulators, standards bodies, approach organizations....), collaboration (partners) and competition.

Leadership comes from providing these customers, users and network 'players' with excellent appropriate experiences throughout a customer life cycle. Note that this life cycle is elliptical, repeating cycle which unfortunately has potential abandonment, loss and attrition points if customer experience is poor compared to expectations and competition.

During the steps a life cycle(e.g. needs identification, awareness: learning; evaluation: deciding: acquisition: using/consuming; re-entry or new purchasing...) there is a touch zone comprising 'touch points' 
where as a company we can influence or manage users or customer experience. We consider ways to improve management of customer or user, there are some practical areas, which we need to consider:

Who: Who should we listen to and understand? Types of customers

What: makes up 'voices' ( spoken, unspoken, thoughts, observations, beliefs, actions)

How: To listen, observe, understand, translate and prioritize messages.

How many: mix and numbers to receive valid messages.

\section{Nature and Scope of Research:}

The present study is based on the data collected from articles and research papers constituting the formation of secondary data of research. On the basis of the data collected, following findings have been identified and obtained. Though various variables/factors influence the concept, the most significant factors considered are mentioned.

Customers are multiplying rapidly. Thus, the rationality underlying the research objective is to provide organization an ability to forecast and plan for customer demand. Today there exits a need for responsible marketing, calling for the study of the economics of long lasting customer relations leading to value creation both to the customers to keep them coming back and to the shareholders, thereby contributing to wealth creation.

The secondary data collected has been utilized to condense the information into number of original variables into a smaller set of composite dimensions (factors). Thus this technique helps to identify important features of the research concept.

\section{Analysis and Secondary research:}

An quantification of selected current e-commerce sites may be conducted to get a perspective on the range of approaches to the issue of trust. Distinct elements and common principles may then be identified. The secondary research provided additional insights developing an approach.

The variables contributing the first factor and their factor loadings are -

TABLE: Factor Study Table

\begin{tabular}{|l|l|}
\hline 1 & Consumer or user \\
\hline 2 & The essence of mechanism for understanding the information required by specific customer interactions \\
\hline 3 & Customer's role \\
\hline 4 & Competitive environment \\
\hline 5 & Customer Touch Zone \\
\hline 6 & An Enterprise data-warehouse \\
\hline
\end{tabular}

\section{Significance:}

The competitive advantage in this study has been measured by analyzing the strengths and weakness of the industry with the application of Porters' competitive framework and PEST.In the context of the study this tool would increase market access by identifying factors of organic decision and as a tool of negotiation and norming. The managers and men in the organization would be able to map these factors by giving it a count adding a conglomerate structure to account development by the principle of Pareto(80:20). It would encourage, leverage consumer research through web based marketing tools and media utilization by posting the factors for discussion to the consumers in the market enabling their conversion into pool of talkers, influencers to arrive at behavioral and demographic value enhancers for identifying stage-specific behaviors' and necessities.

As families make the transition from one stage of lifecycle to another importance given to different variables in each stage is different. The comparison of the results of factor analysis for different stages reveal the changing roles in transition of family lifecycle to produce new market segments. The organization would be able to extract components for forecasting structural composition for savings, measuring diversification, sound project planning. Use case studies for quantification. Simple percentages, cross tabulations, growth rates can be used as a simplistic tool for analyzing data. In this phase, a bulletin board discussion may be hosted with the experts in the fields of web site design, marketing and product development.

\section{The CLM Facts:}

"The purpose of customer life cycle is to define and communicate the stages through which a customer progresses when considering, purchasing and using products, and the associated business processes a company uses to move the customer through the customer life cycle. The map of CRM technology to the customer life cycle,presented in the next parts of this series, provides a mechanism for prioritizing systems projects and for understanding the information required by specific customer interactions".

The Customer life cycle is depicted in the figure1 
Figure 1:Global Marketplace

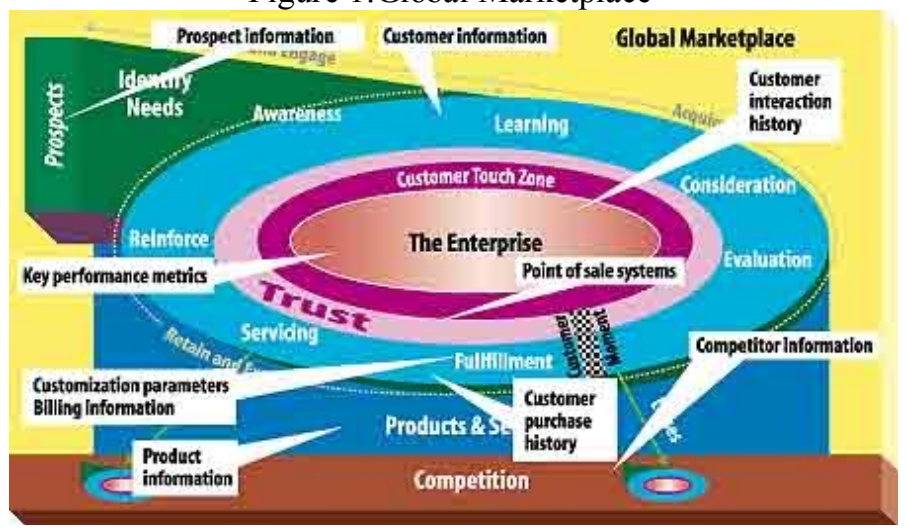

1]This customer life cycle is generic; the stages shown represent thought processes for typical customers and companies.

2] While these stages may or may not change, it is likely that the business processes that map to these stages will differ from company to company.

3] Differences will also exist based on the product under consideration - the cycle for buying soap is different from the cycle for buying a car.

4] We recommend that you start with this generic customer lie cycle, compare it to the reality in your organization and adapt it as needed.

\section{Role of Four Pillars of CLM:}

The Customer's Role: The customer life cycle is depicted as a circle or eclipse to represent that it is truly a cycle, one that you want your best customers to move through again and again. When a customer is considering the purchase of a product or service ( a "prospect" in the early stages of the customer life cycle), he or she goes through a predictable series of thought processes. These processes are shown, just inside the circle on the customer life cycle.

The Enterprise Role: The outer most circle represents the flip side of the customer stages . Theses are the processes that your organization undertakes to move through the customer life cycle. Once you determine the mind set, and thus the possible behaviours, of your customers as they move through the customer life cycle, you can identify the interactions or business processes your organization has with these customers. The business processes conducted by your organization fall into the following general categories: intrude and engage, acquire, retain and expand.

The Competitive Environment: While the customer life cycle activities sit upon the foundation of products and services, the customer life cycle itself is driven by the principles of competition. A competitor is any enterprise that offers products and services that rival your own. The need for ( and value of) CRM is influenced by the amount of competition faced by an organization or industry. The competitive environment as the driving factor in CRM is represented in the customer life cycle by the position of competition.

The Customer Touch Zone: A customer touch is any interaction between the customer and the enterprise. Either the company or the customer can initiate customer touches. The management part of CRM is the identification and administration of all customer interactions to the satisfaction of the customer and the longterm profit of the organization. Each customer touch, real time or through batch processes, face-to-face or through media, is accounted for in the customer life cycle.

\section{Integrating CLM \&CLV:}

The concept being knowledge driven helps in the establishment of the Intelligence System primarily in the arena of marketing, towards the achievement of organizations goals, through business intelligence system[MIS, ERP, CRM, EMM(Enterprise marketing management), BPR etc.].Thus the rationality underling CLM objective is to provide organization an ability to forecast and plan for consumer demand and suggest value added high margins services and not wait for customer to come to for service and new request. Today there exists' a need for responsible marketing, calling for the study of economics of long lasting customer relationships leading to value creation both to the customers to keep them coming back and to the shareholders[ thereby] contributing to wealth creation rather than profit booking].

Now that you have found your customer, it is important to find ways to add value to the relationship. Keep in mind that value is in the mind of the customer and find out what they perceive valuable. Alternatively, how to use customer lifetime value. Do we know what an average customer is truly worth to your company? 
By calculating your customer lifecycle value, you will be able to answer that question. 'CLV is the amount of profit a customer delivers to your company for as long as the customer is buying from you. It's typically calculated as the net present value ( the value in today's dollars) of the profit you'll earn all of a customer's purchases over time.' When you know your CLV , you have an extremely powerful tool that helps with:

1. Targeting: You will know which customer segment delivers the most profit to your company and you can focus more marketing efforts toward that particular segment.

2. Return on Investment: By using CLV in your ROI calculations for marketing campaigns, you will have much more accurate measure of campaign performance.

3. Customer retention: You can determine how much you can spend to profitably retain customers.

4. Single-customer profitability: You can calculate the profitability of an individual customer. Thereby paving a way for tracking customer life cycle graph. This requires careful analysis of purchase pattern and time spent with the organization by the customer. \{The statistical tools lie time series, co-relation and deviation studies can be used].

\section{Implications for Managers and Sector Academia:}

1 CLM provides organization an ability to forecast and plan for customer demand and suggest value added high margins services and not wait for customers to come for service and new request.

2 Another advantage for CLM is closer interaction with customer, to identify the true economics of service and calculate the service cost pricing for different level of service offerings.

3 This customer information is the foundation for the organization customer relationship pyramid. It is from the point of view of that player whose intention is to benefit from increased knowledge of costs in order to achieve an increased control over their value-chain and profit-margins.

4 Facilitating decision making for marketing practitioners.

5 It represents a growing complexity, necessitating even more complex costing and management methods than the recent innovations.

6 It calls for managerial cognition, providing promising possibilities for integrating and of understanding strategy development in volatile conditions.

7 To build positive and lasting relationships with customers and other stake holders. It is a customer-centric, data driven approach to marketing.

8 It is time-centric process. It is an evolutionary and dynamic phenomenon over time. Therefore, it is important to utilize research techniques such as longitudinal panels, which measure changes over time; we need time series data similar to what psychologists use in measuring or econometricians use to measure customer cycles and trends.

9 The lessons learned from previous efforts, both successful an unsuccessful, of various marketing domains that have tried to become disciplines provide a good road map of how to evolve relationship marketing into a distinct discipline and unraveling the latent facets like customer life cycle management. Thus, it calls to integrate knowledge and relationship as key components foe strategic business decision. It articulates the concept with its own distinct properties.

\section{Conclusion:}

In this age of diversity, marketers are being rudely awakened to the erosion of the mass market. A massive upheaval in the social landscape has led to the fragmentation of the mass market. Marketers find that the traditional marketing method are no longer so effective as they used to be The search is on for new and more appropriate methods.

Niche marketing and relationship marketing are two of the most talked-about methods. Each of these strategies was developed from a different perspective, and a little attention was paid to the possible synergy between the two. This is the first step in trying to integrate the modern concepts of relationship marketing and database marketing leading to the emergence of the hidden tool called customer lifecycle managementsynergizing knowledge with relations.

This study develops a perceptual integrated management framework for building customer life cycle based on consolidating and deciphering of customer knowledge. The framework consists of four major components of management: organizational knowledge, customer knowledge workers, knowledgement management process, and information technology. Based on the framework, this study proposes a stage model of customer lifecycle management encompassing the initiation, propagation, integration and networking stages. This article develops a customer process model by integrating these ideas with the life-cycle concept. The model is universal in applicability and can be implemented across the product-service continuum.

The people with the most stake in your company are your customers- Jeff Taylor 
Serve them with a smile

\section{References:}

[1]. salesforce.com,inc. Customer Relationship Management.

[2]. http;//www.ttm.co.uk

[3]. http://www.jimnovo.com

[4]. \{Building the customer-centric enterprise- Data warehousing techniques for supporting customer relationship management, published by John Wiley \& Sons\} Claudia Imhoff's monthly column.

[5]. Data mining techniques for customer relationship management Chris Rygielski a, Jyun- Cheng Wang b, David C.Yen a , *a Department of DSC and MIS, Miami University, Oxford, OH , USA b Depatment of Information management National Chung-Cheng University, Taiwan, ROC.

[6]. www.emerald.com

[7]. www.marketingteacher.com

[8]. A stage model of organizational knowledge management : a latent content analysis Jang-Hwan Lee and Young-Gul Kim, Korea Advanced Institute of Science and Technology, 207-43 Cheongryangri-dong, Dongdaemoon-gu, Seoul, 130-012, South Korea. 